\title{
El SALVADOR: ENTRE EL CONTINUISMO Y LA DESILUSIÓN
}

\author{
El Salvador: Between Continuity and Disappointement
}

\author{
ROODY RÉSERVE* \\ Pontificia Universidad Católica de Chile
}

\begin{abstract}
RESUMEN
2010 y 2011 han sido particularmente convulsivos para El Salvador. En 2010 la crisis institucional y el enfrentamiento entre los poderes Legislativo y Judicial marcaron la agenda. Cuatro magistrados de la Corte Suprema de Justicia fueron considerados en desacato con lo que se considera como el primer órgano del Estado en El Salvador. De no haber sido por fuertes presiones de la sociedad civil, los diputados habrían destituido a los magistrados por haber intervenido en materia electoral, que ellos consideran de su estricta incumbencia. 2011 terminó con la decisión del Presidente de militarizar la seguridad pública. Esto desencadenó una avalancha de renuncias de los miembros de su gabinete de seguridad y enfrentamiento con organismos de derechos humanos locales. Así, se abortó el experimento de impulsar una concepción de izquierda, novedosa para El Salvador, en materia de enfrentamiento de la violencia. De paso, durante estos dos años el desencuentro político entre el presidente Mauricio Funes y su partido el Frente Farabundo Martí para la Liberación Nacional (FMLN) también ha marcado el ritmo de la vida política.
\end{abstract}

Palabras clave: Corte Suprema de Justicia, Legislativo, violencia, seguridad pública, sociedad civil, crisis.

\begin{abstract}
2010 and 2011 have been two convulsive years for El Salvador. In 2010 the institutional crisis and confrontation between the Legislative and Judicial Organs were the most salient political events. Four Judges from the Constitutional Court were considered in contempt with the Legislative, which is considered in El Salvador as the first Organ of the State. Had it not been for intense pressures from organized actors in the Civil Society, the deputies would have dismissed the judges, for having dared to decide in electoral matters, consider to be the sole responsibility of the legislators. 2011 ended with the president's decision to put the military in charge of public security. This decision triggered an avalanche of resignation from members of his security cabinet and harsh criticism of the local human rights organizations. In 2011 the experiment to promote a leftist and new concept to curb violence in El Salvador was aborted. During these two years clashes between the President, Mauricio Funes and its party Frente Farabundo Martí para la Liberación Nacional (FMLN) have kept attention of observers.
\end{abstract}

Key words: Supreme Court, Legislative, violence, public security, civil society, crisis.

* Agradezco a Germán Bidegaín y a un evaluador anónimo de la Revista de Ciencia Política por sus comentarios que han ayudado a mejorar este texto. 


\section{INTRODUCCIÓN}

Serias desavenencias entre la Sala de lo Constitucional de la Corte Suprema de Justicia y los partidos políticos con representación en la Asamblea Legislativa han marcado las relacionales institucionales en El Salvador desde 2010. Cuatro magistrados, de los cinco que componen dicha sala, ganaron el oprobio de la clase política entera por haber declarado inconstitucional una disposición del Código electoral que estipulaba la prohibición de candidatos sin afiliación partidaria a las elecciones legislativas y consagraba las listas cerradas y bloqueadas. Aun cuando desde la integración de la primera Corte en tiempos democráticos los políticos han criticado decisiones puntuales de los miembros de la Sala de lo Constitucional, específicamente en temas relacionados con la protección de los derechos humanos, es primera vez que casi todos los partidos se concertaron para repudiar unas decisiones de dicha sala. En las líneas que siguen se argumenta que, para explicar el comportamiento estratégico de los magistrados respecto de demandas controversiales de inconstitucionalidad, hay que fijarse en el contexto político social en que resuelven las demandas. En este sentido, se sostiene que los magistrados de la Corte Suprema no son ningunos fantásticos extraterrestres, como denominan localmente a los cuatro miembros de dicha institución que desafiaron a los partidos, sino individuos estratégicos que miran el estado de la opinión y las condiciones objetivas de la política para resolver las demandas de inconstitucionalidad. Esta sería la razón por la que en 2010 y 2011 fueron posibles las declaraciones de inconstitucionalidad que molestaron tanto a los políticos.

Por otro lado, la violencia siguió siendo la principal preocupación de los salvadoreños. 2011 ha sido el segundo año más violento en un decenio. La respuesta del gobierno ha sido más mano dura, con el uso irrestricto de los militares en tareas de seguridad civil. Se les han confiado a estos tareas de patrullajes al lado de los policías. Se les ha encargado el control de las cárceles. El presidente Mauricio Funes les ha entregado el Ministerio de Seguridad y la dirección de la Policía Nacional Civil. Como han observado algunos analistas: "Funes ha hecho en 18 meses, en materia de involucramiento de las fuerzas armadas en tareas de seguridad civil, lo que ARENA no se atrevió a hacer en 20 años" (UCA, 2012). En este sentido, el Presidente salvadoreño decidió desde su despacho la vuelta de los militares a la política. Aquí se discuten las principales explicaciones que se han dado sobre el origen de la violencia en El Salvador y que motivarían el recurso a los militares en la lucha en contra de la delincuencia. Se ponen de relieve las tensiones existentes entre los estudios académicos que privilegian explicaciones estructurales de largo plazo frente a la necesidad de resultados inmediatos de los políticos y sus electores. Se muestra, en un análisis local de las tasas de homicidios, en los 14 departamentos del país, que queda mucha tela que cortar para llegar a una respuesta definitiva acerca de las causas de la criminalidad en El Salvador. Sin aventurar aun conclusiones definitivas, este trabajo muestra las principales dificultades con que se tienen que enfrentar quienes quieren comprender el fenómeno de la violencia en Centroamérica.

En marzo de 2012 se iban a celebrar elecciones legislativas y municipales. En buena medida, el impasse entre la Corte y los diputados tenía como trasfondo estas elecciones. Al principio, todo fue eclipsado por la lucha entre la Sala de lo Constitucional y los partidos. 
Pero una vez que quedó claro que los magistrados tenían apoyo social suficiente como para que quienes votaran a favor de su remoción pagaran un precio político alto, los actores empezaron a ajustar su estrategia política en consecuencia. Finalmente la elección se celebró bajo las nuevas reglas dictadas por los magistrados. Se aceptaron candidatos independientes y los partidos tuvieron que desbloquear las listas de candidatos para que los electores pudieran decidir si respaldaban a todos los candidatos propuestos o algunos de estos, y en qué orden. Sobre este tema en particular, este trabajo se limita a constatar los resultados electorales. Llama la atención que ningún candidato independiente logró contestar la hegemonía de los partidos y que tampoco los electores hayan desordenado las listas presentadas por los partidos.

Finalmente se concluye con una breve reflexión sobre el impacto del fracaso de la izquierda en materia de combate a la delincuencia, junto con la crisis institucional entre políticos y jueces, sobre la estabilidad del sistema político salvadoreño. Se argumenta que El Salvador se encuentra en un momento decisivo de su historia, luego de más de dos décadas de haber firmado los Acuerdos de paz. Los acontecimientos de 2011 muestran que los partidos políticos tienen que prestar atención al desgaste progresivo del sistema político, luego de veinte años de democracia.

\section{LA CRISIS INSTITUCIONAL}

Todo empezó, en realidad, el 29 de julio de 2010. Ese día la Sala de lo Constitucional (en adelante la Sala o la Corte) de la Corte Suprema de Justicia (CSJ) declaró inconstitucional los artículos 215 inciso $2^{\circ}$ numeral 5; inciso $1^{\circ} ; 238 ; 239$ inciso $1^{\circ} ; 250$ inciso $1^{\circ} ; 253-C$, inciso $3^{\circ}$; y 262 inciso $6^{\circ}$ del Código Electoral. Fundamentalmente, para la Corte, es inconstitucional exigir constancia de afiliación partidaria a los candidatos a elección para la Asamblea Legislativa. Además, considera que las listas cerradas y bloqueadas menoscaban los derechos de los ciudadanos a ejercer el sufragio de manera libre ${ }^{1}$. Los responsables de los partidos interpretaron dicha decisión como una intromisión indebida de los magistrados en una materia que les corresponde exclusivamente.

La primera reacción de los partidos fue aprobar una reforma constitucional que estipulara claramente el requisito de afiliación a un partido político como condición para ser candidato tanto a la Asamblea Legislativa como a los concejos municipales ( $E l$ Faro, 2010). Luego convocaron a ex presidentes de la Corte Suprema de Justicia para que analizaran la decisión de los magistrados y que dijeran si estaba reñida o no con la Constitución. De esta manera, buscaban argumento para la destitución de dichos magistrados. Por lo menos dos ex presidentes de la CSJ dieron la razón a los diputados. Manifestaron su desacuerdo con la sentencia de la Sala y abogaron claramente por la destitución de dichos magistrados. Hubo quien incluso sostuviera, Mauricio Gutiérrez

1 Ver sentencia de la Corte Suprema en: http://www.elfaro.net/attachment/384/Sentencia $\% 20 \% 2061-2009 \% 20$ candidaturas\%20independientes.pdf?g_download $=1$ 
Castro, ex presidente de la Corte entre 1989 y 1994, que "si fuera diputado no cumpliría con la resolución" de los magistrados (Aguilar, 2010).

Las presiones sobre los cuatro ${ }^{2}$ magistrados de la Sala de lo Constitucional arreciaron durante 2011. Ellos siguieron invalidando las decisiones legislativas que contravenían su sentencia. Los diputados, por su lado, siguieron blandiendo la amenaza de la destitución. Finalmente, aprobaron el decreto 743 que exigía la unanimidad en todas las decisiones que tomaran los miembros de la Sala. Como para recalcar que el decreto iba dirigido específicamente a los actuales miembros de la Corte Suprema de Justicia, los legisladores estipularon que caducaba el 31 de julio de 2012, al cumplirse el período de estos cuatro magistrados en la Sala de lo Constitucional. La decisión de los diputados generó una reacción generalizada de sectores organizados de la ciudadanía, que se manifestaron en contra de la arbitrariedad de los dirigentes políticos. Organizaciones de distintas tendencias ideológicas denunciaron "el golpe" de los diputados. ${ }^{3}$ La Asociación Nacional de la Empresa Privada (ANEP), generalmente cercana a los partidos de tendencia de derecha, dijo encontrar "grandes vicios de inconstitucionalidad [en el decreto]". Además, denunció la manipulación "del poder y las leyes para resolver los problemas particulares de los partidos o del Gobierno" (Co-Latino, 2011). La Fundación de Estudios para la Aplicación del Derecho (FESPAD), de tendencia izquierdista, de igual modo, se puso del lado de los magistrados de la Sala. Consideró que el decreto 743 "es inconstitucional; por lo cual es correcto que los Magistrados lo declaren inaplicable" (FESPAD, 2011). Así, el decreto y la amenaza de destitución de los magistrados por intromisión en tareas legislativas y desacato a los diputados generaron una movilización transversal de la sociedad civil en contra de los diputados, quienes finalmente tuvieron que dar marcha atrás, abrogando dicho decreto.

Cuadro 1: Algunos hechos rescatados de la cronología de enfrentamiento entre CSJ y diputados

Fecha

Fecha

29 de julio de 2010
La Corte Suprema declara inconstitucional los artículos 215 inciso $2^{\circ}$ numeral 5; inciso $1^{\circ} ; 238 ; 239$ inciso $1^{\circ} ; 250$ inciso $1^{\circ} ; 253-C$, inciso $3^{\circ} ;$ y 262 inciso $6^{\circ}$ del Código Electoral. Dichos artículos exigían la pertenencia a un partido político para ser candidato a diputado y definían que las listas eran cerradas y bloqueadas.

2 La Sala de lo Constitucional está conformada por cinco magistrados. Pero solo cuatro de los cinco magistrados han votado a favor de las sentencias más controversiales relacionadas con el control de los partidos sobre el sistema electoral (El Faro, 2011).

3 Ver El Faro 2011: "35 organizaciones cívicas se unen contra decreto que ataría a Sala de lo Constitucional”. http://www.elfaro.net/es/201106/noticias/4349/ 
Fecha

12 de agosto de 2010

16 de diciembre

de 2010

$6 / 06 / 2011$

$3 / 10 / 2011$

$25 / 10 / 2011$

Hechos

Sin haber sido notificados por la Corte Suprema de Justicia de su sentencia, los diputados aprueban una reforma constitucional que tendría que ratificarse en la próxima legislatura 2012-2015. Dicha reforma estipula la obligación de pertenecer a un partido para postular a cargos de elección tanto a nivel municipal como de la Asamblea Legislativa. Además, establece que el orden de los candidatos en la lista lo establecen los partidos.

La Asamblea Legislativa aprueba darle a la Junta Directiva la potestad de crear una comisión ad hoc de revisión de la sentencia de la Corte Suprema de Justicia. Dicha comisión que empezó a reunirse el viernes 20 de agosto acordó invitar, entre otros personajes, a ex magistrados de la Corte Suprema de Justica para analizar la decisión de la Sala de lo Constitucional.

Los partidos ARENA y FMLN aprueban unas "Disposiciones para la postulación de candidaturas no partidarias en las elecciones legislativas". Este decreto establece, entre otras cosas, que los candidatos independientes deben presentar entre seis mil y 12 mil firmas, las cuales tienen que recolectar en un período de 25 días, según el número de electores residentes en la circunscripción en la que se postulan.

La Asamblea Legislativa aprueba decreto 743 que reforma la Ley Orgánica Judicial. Dicho decreto obliga a la Sala de lo Constitucional a decidir con la aprobación unánime, y no con la mayoría de sus integrantes, tal como antes se hacía.

Sala de lo Constitucional de la Corte Suprema declara inaplicable decreto 743. Según los magistrados: "Llegar a la solución que suscita mayor acuerdo, donde la exigencia de 5 votos sobre 5 posibles se puede convertir en un obstáculo insuperable en casos de trascendencia nacional; pues, ante la conformación subjetiva determinada por las distintas corrientes del pensamiento jurídico, no es posible unificar el total de votos en cada decisión".

La Corte Suprema declara inconstitucional los requisitos para candidatos independientes aprobados por los legisladores.

Los legisladores aprueban nuevas disposiciones para la postulación de candidaturas no partidarias en elecciones. La Corte objetó el corto plazo, 25 días, de recolección de firmas otorgado a los independientes y la prohibición de postulación por el período siguiente a diputados que hayan abandonado su partido durante una legislatura.

Fuente: elaboración propia a partir de datos periodísticos de la Asamblea Legislativa y de la CSJ.

Este episodio y otros ${ }^{4}$ captaron la atención de toda la población y los actores políticos salvadoreños. La extrañeza venía del hecho de que desde los Acuerdos de Paz la Sala

4 Elaine Freedman, en la Revista Envío, hace el siguiente balance de la actuación de estos magistrados: "Los cuatro nuevos magistrados entraron a sus cargos asumiendo una tremenda mora judicial, que incluía 700 denuncias engavetadas contra jueces. Removieron jefaturas vinculadas con el nepotismo, el despilfarro y la 
de manera específica y la Corte Suprema de un modo más general habían servido como comparsa de los partidos políticos. Desde la sociedad civil se denunciaba regularmente la falta de independencia de la CSJ frente a los políticos. La aprobación de leyes como la dolarización de la economía salvadoreña, la mano dura, etc., con la venia de los magistrados, había fortalecido esta sensación. A tal punto que ya en 2005 FESPAD declaraba que "el análisis evidencia el deterioro de la institucionalidad del país; intereses particulares y los acuerdos partidarios se han sobrepuesto a los mandatos constitucionales; el funcionamiento de las instituciones está respondiendo a lo que mejor conviene a los grupos de poder. Lo cual evidencia un retroceso de los avances que los Acuerdos de Paz ofrecieron en el camino hacia la democracia, la cual actualmente se limita al hecho de que la ciudadanía puede ejercer el derecho al sufragio en forma simple, pues no existen mecanismos de participación ciudadana efectiva, en un contexto nacional que no refleja condiciones de verdadera democracia" (FESPAD, 2005).

La pregunta, entonces, que se hacen los salvadoreños, a raíz de los acontecimientos de 2011, es qué puede explicar este nuevo comportamiento de los magistrados. Dado el carácter repentino, sin coherencia con decisiones anteriores de la CSJ, de allí el mote de "fantásticos" adosado a los magistrados "rebeldes". Un apodo, según Freedman (2011), inventado por "Salvador Samayoa, ex dirigente del FMLN y funcionario del gobierno de Francisco Flores", ex presidente de la República por el partido ARENA entre 1999 y 2004. De algún modo, dada la novedad que supone una Corte que desafía los intereses de los políticos, se asume que sólo podrían ser unos seres extraterrestres, desconectados de la realidad salvadoreña. Las explicaciones para este singular comportamiento han privilegiado un relato de tipo personalista. Se ha puesto el énfasis en la figura de los magistrados, en sus características personales, como académicos, tres de ellos, y además vinculados con el mundo de los derechos humanos. In fine, lo que se recuerda es que, en anteriores ocasiones, la Sala de lo Constitucional siempre se había plegado a los intereses de los partidos políticos por encima de los ciudadanos. En efecto, desde hace algún tiempo se viene denunciando que la democracia salvadoreña instaurada luego de los Acuerdos de Paz de 1992 se ha convertido en una pura democracia electoral (PNUD, 2004) o un elitismo competitivo (Artiga, 2004). El mérito particular de estos cuatro magistrados estaría en su valentía y su independencia para enfrentarse a los partidos.

Sin embargo, sostenemos que no es suficiente con destacar la particular valentía de los cuatro magistrados de la Sala de lo Constitucional para entender -habiendo sido

\footnotetext{
corrupción, impulsaron una investigación sobre 32 plazas vendidas, y promovieron medidas de austeridad. Todo esto provocó malestar en sus colegas, los magistrados de otras salas. Posteriormente, la Sala de lo Constitucional entró en choque con el Ejecutivo cuando prohibió el traslado de fondos de ministerios a la bolsa de "gastos imprevistos" del Presidente, borrando así de un plumazo la infame "partida secreta", pero también la flexibilidad presupuestaria. Obligó a la Asamblea Legislativa, contra su voluntad, a modificar la Ley Electoral para inscribir candidaturas independientes e incluir fotografías de candidatas y candidatos en las papeletas de votación, inicialmente en sustitución de las banderas partidarias. Cancelaron a los tradicionales partidos de derecha Partido de Conciliación Nacional (PCN) y Partido Demócrata Cristiano (PDC) por haber recibido menos del 3\% de los votos en la elección presidencial de 2004 y destituyeron a los magistrados de estos partidos en el Tribunal Supremo Electoral (TSE)" (Freedman, 2011).
} 
ellos mismos escogidos por los diputados, según los mismos criterios de prebendas y reparto de influencias que se usaron para nombrar a sus predecesores- por qué ellos resultaron diferentes. Un primer elemento complementario de respuesta, a nuestro juicio, se encuentra en el contexto general mismo de su elección. Aun cuando habían sido elegidos de la misma forma que sus antecesores, estos magistrados fueron nombrados justo después del triunfo electoral en la rama ejecutiva de un presidente de izquierda. Se trata de un contexto de ilusiones de cambio, en que una gran mayoría de ciudadanos manifestaron su deseo de ver una mejora en la conducción de la política en el país. Es plausible afirmar que los magistrados actuales de la Sala de lo Constitucional están inmersos en un contexto sociopolítico diferente al de sus predecesores. No es la primera vez que se reclaman cambios profundos en la conducción política salvadoreña, ${ }^{5}$ pero es la primera vez que se materializa en la llegada de un actor político distinto al de los últimos 20 años en la presidencia de la República. Así, postulamos, se les hizo más fácil a los actuales miembros de la Sala de lo Constitucional dar una muestra de coraje, en comparación con las salas anteriores. Aprovechando el ambiente de cambio pudieron también manifestar su desacuerdo al manejo exclusivo de la política por parte de los partidos, instaurado desde la firma de los Acuerdos de Paz de 1992.

En segundo lugar, otro elemento de contexto que sin duda coadyuvó a esta extrañeza de comportamiento de los magistrados ha sido el proceso de reacomodo que ha vivido el sistema de partidos salvadoreño, especialmente la derecha, luego de las elecciones de 2009. Esta crisis de los partidos de derecha terminó de convencer, a quien tuviera dudas, que el monopolio de los partidos en la vida política podía tocarse. La derrota electoral de ARENA en las elecciones de 2009 trajo consigo una profunda división interna en el partido, que culminó con la división de su bancada legislativa ${ }^{6}$ y la expulsión del ex presidente de la República Antonio Saca de las filas de su partido (FUSADES, 2010). Los legisladores que se separaron de ARENA fundaron un nuevo partido, que pronto se convirtió en el principal socio del presidente Funes, a veces incluso en desmedro del FMLN, el partido que llevó al mandatario a la presidencia (Aguilar, 2011). En este contexto, puede argumentarse, los magistrados de la Sala de lo Constitucional, al quitar el monopolio de la representación legislativa a los partidos, aprovecharon un ambiente de incertidumbre que parecía cuestionar la idea de que los partidos son el único camino para lograr la representación de los intereses en la sociedad. Precisamente uno de los argumentos que enarbolaban los legisladores que se separaron de ARENA era su obligación de alejarse de un partido que ya no representaba el sentir de la población.

Además, en algún sentido, se venía imponiendo la idea de que recurrir a actores externos a los partidos era una buena señal de moderación política. Durante la campaña para la elección presidencial de 2004 el candidato de ARENA, Antonio Saca, destacó

5 Una muestra de ello es que esta demanda de inconstitucional que finalmente resolvió la Sala de lo Constitucional fue presentada en el 2003 por el ciudadano Félix Ulloa, ex magistrado del Tribunal Supremo Electoral, 19941999, como representante del partido FMLN.

612 diputados abandonaron las filas de ARENA y fundaron el partido Gran Alianza Nacional (GANA). Aun cuando el ex presidente Saca no se ha manifestado formalmente como su miembro, se le relaciona con dicho partido, por cuanto está compuesto por legisladores y colaboradores afines durante su mandato. 
principalmente su condición de outsider de los partidos, como empresario, presidente de la Asociación Nacional de la Empresa Privada (ANEP). Esto, a su juicio, le ofrecía una mejor capacidad de comprensión de los problemas sociales y así evitar la politiquería que había permeado a los actores institucionales partidarios. De igual modo, el FMLN pudo ganar la presidencia en el 2009, gracias a que postuló a Mauricio Funes, un periodista, que se había destacado por su independencia respecto de los partidos. Todo ello, en un contexto en que los partidos aparecen reiteradamente, cada año un poco peor, como las instituciones en las que menos confían los salvadoreños. Así, se puede comprender que al momento de dirimir la constitucionalidad de los artículos que consagran el dominio de los partidos sobre la representación política en la Asamblea Legislativa, los magistrados de la Sala ya tenían un ambiente propicio para una eventual decisión en contra de los dirigentes partidarios.

\section{III. ¿LA VIOLENCIA COMO PROBLEMA SIN SOLUCIÓN?}

Otro tema que marcó el 2011 en El Salvador fue el nivel de violencia. El número de homicidios de 2011 ha sido el segundo más alto en una década, sólo superado por el 2009, un año electoral, cargado de simbolismo, que vio triunfar al primer gobierno de izquierda en las elecciones presidenciales. Así también lo han señalado los salvadoreños que han declarado en un $65 \%$ que el principal problema del país ha sido la violencia, la

Figura 1: Personas que se han declarado víctimas del crimen en perspectiva comparada

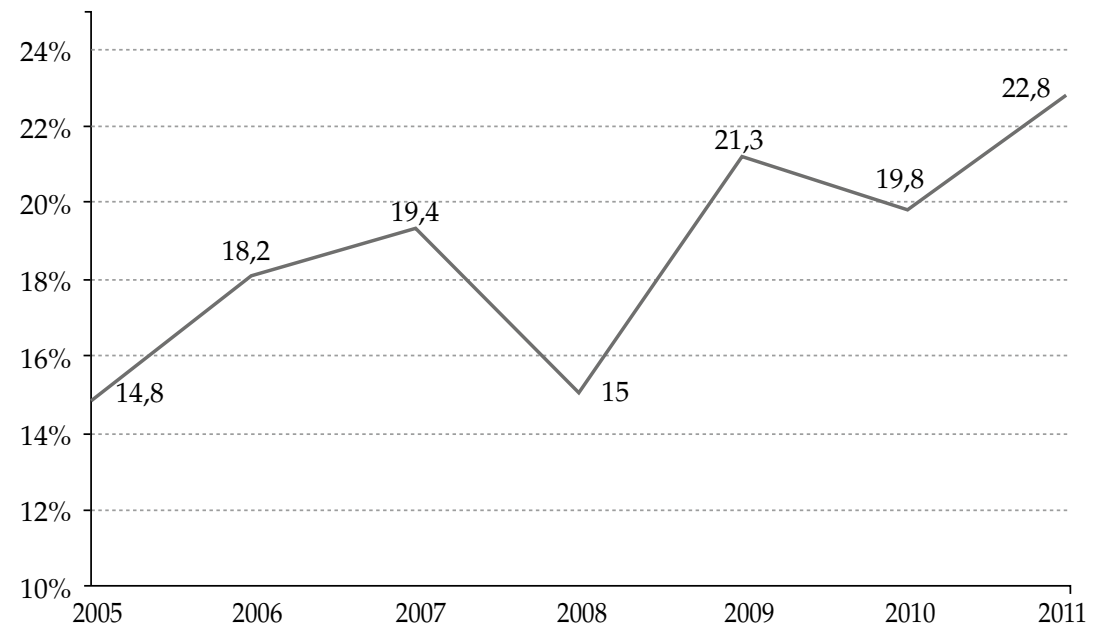

Fuente: tomado de IUDOP (2011).

cual, más de 67,4\% ha señalado que ha aumentado (IUDOP, 2011). La Figura 1 presenta datos del porcentaje de personas que dijeron haber sido víctimas de la delincuencia en 
un período de siete años. Como puede observarse, 2011 tiene las cifras más altas para este período. Incluso supera las de 2009 que, como veremos más adelante, tiene el récord de asesinatos en una década.

Como respuesta al aumento de la violencia (ver su evolución para los últimos seis años en el Cuadro 2) y tal vez a la caída constante en su aprobación por parte de los ciudadanos, como se observa en la Figura 2, Mauricio Funes ha vuelto a favorecer la opción represiva de mano dura. En primer lugar, aumentó la presencia militar al lado de los policías. ${ }^{7}$ Pasó la responsabilidad de las cárceles a los militares. Designó a su ministro de Defensa, un general recientemente desvinculado de las fuerzas armadas, para hacerse cargo del Ministerio de Seguridad Pública, en lugar de un militante del partido Frente Farabundo Martí (FMLN) que lo postuló a la presidencia. Y pasó a retiro a otro general, para hacerse cargo de la dirección de la Policía Civil. Una serie de decisiones que según muchos llevan a la militarización de la seguridad pública en El Salvador (UCA, 2012). Muchas organizaciones de derechos humanos e intelectuales criticaron las decisiones en materia de seguridad pública del Presidente (Cruz, 2011; Ribera, 2012), porque no sólo siguen en la misma línea de la mano dura que practicó el partido ARENA durante 20 años y que no dio resultados, sino también por el peligro de una vuelta al pasado en que los militares violaban sin contemplación los derechos humanos con el pretexto de combatir la criminalidad. Además, según las organizaciones de derechos humanos, lo único que ha hecho el Presidente es reciclar una vieja estrategia que ha mostrado su fracaso en todas partes (UCA, 2012; FESPAD, 2011, López, 2011).

Según algunos reportes han aumentado los casos de violación de los derechos humanos. Datos aportados por la Procuraduría para la Defensa de los Derechos Humanos revelan un aumento en las denuncias de violación de los derechos humanos en contra de la Policía Nacional Civil. Las denuncias han subido en un 14\% respecto del año anterior, pasando de 1.505 a 1.705 (La Prensa Gráfica, 2011). También hay reportes de asesinatos sumarios por parte de los militares implicados en tareas de seguridad civil. En este respecto, por ejemplo, las denuncias en contra de los militares en la Procuraduría para la Defensa de los Derechos Humanos aumentaron, en un 149\% (La Prensa Gráfica, 2011).

Todo ello ha vuelto a instalar el debate acerca de las causas de la violencia y la mejor manera de combatirla. ¿Tiene que aplicarse más mano dura o hay que invertir en el fortalecimiento institucional y en tajar los problemas sociales? Desde que al fin de la guerra el tema de la violencia social empezó a asomarse no ha habido coincidencia entre los actores sociales y políticos de cómo abordarlo. La derecha, en el poder por más de 20 años, primero negó la existencia de tal problema, luego privilegió la estrategia de Mano Dura, ${ }^{8}$ pero siempre con

7 Sobre el uso de los militares en tareas de seguridad civil en Centroamérica ver: Informe sobre Derechos Humanos y Conflictividad en Centroamérica 2010-2011" del Equipo Regional de Monitoreo y Análisis de Derechos Humanos en Centroamérica.

$8 \quad \mathrm{Al}$ igual que lo hicieran sus antecesores, Funes también aprobó su particular Ley Antipandillas, en el contexto de la mano dura. Así, se aprobó en septiembre de 2010 la Ley de Proscripción de Pandillas o maras. “La nueva normativa, a lo largo de 11 artículos, define como ilegal la existencia de las pandillas, el apoyo y financiamiento a las mismas, y establece las sanciones para aquellas personas a las que se compruebe participación o colaboración con este tipo de agrupaciones, entre las que menciona a la "Mara Salvatrucha o MS-trece, Pandilla Dieciocho, 
Figura 2: Evolución de la evaluación del presidente Funes

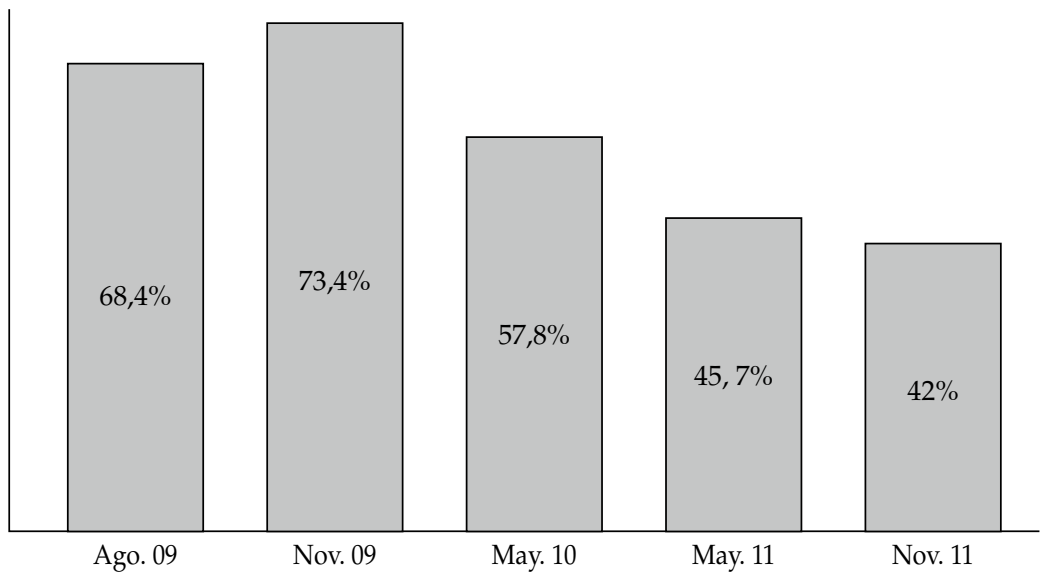

Fuente: tomado de IUDOP (2011).

pocos resultados. La izquierda y la sociedad civil organizada, generalmente de tendencia de izquierda, por su parte, siempre han abogado que la violencia es un problema social, relacionada con la pobreza, la desigualdad prevaleciente en el país, la debilidad de las instituciones y la historia violenta nacional (Cruz, 1997; Cruz y González).

El triunfo de la izquierda en las elecciones presidenciales de 2009 generó muchas expectativas. Tanto la población como las organizaciones sociales más críticas de la estrategia de combate al crimen de las administraciones anteriores esperaban que se empezara a poner en práctica una visión más integral de combate a la delincuencia. De hecho, el Presidente inició dando la responsabilidad del Ministerio de Seguridad Pública a un ex comandante del FMLN, Manuel Melgar, uno de los principales críticos de la acción de la derecha en materia de seguridad pública. Nombró como director de la Policía Nacional Civil a un policía de carrera, asociado a la izquierda. La inspectoría general de la Policía, un cargo de mucha relevancia para el control interno de la institución, muchas veces acusada de tener en sus filas a policías corruptos protegidos por su cercanía con el ex partido de gobierno, fue confiada a una abogada relacionada con el mundo de los derechos humanos. El puesto de viceministro de Seguridad recayó en un abogado relacionado con la Universidad Centroamericana José Simeón Cañas (UCA) y una de las instituciones más emblemáticas en la lucha por los derechos humanos en El Salvador (el Instituto de Derechos Humanos de la UCA).

Efectivamente, este equipo empezó con un proceso de depuración de la Policía Nacional Civil (PNC). Se destituyó a muchos policías acusados de corrupción. En 2010, a un año de haber tomado el control del Ejecutivo, el presidente Funes anunciaba que se había destituido a 237 policías y que más de mil estaban siendo investigados por ser "funcionarios que deshonraron su posición de servidores públicos y se pusieron al 
Cuadro 2: evolución de los homicidios a lo largo de varios años

\begin{tabular}{cc}
\hline Homicidios por cien mil habitantes & Año \\
\hline 69 & 2011 \\
64,7 & 2010 \\
70,8 & 2009 \\
51,8 & 2008 \\
57,3 & 2007 \\
64,5 & 2006 \\
62,9 & 2005 \\
\hline
\end{tabular}

Fuente: elaboración propia a partir del informe Estado de la Nación (2011).

servicio de la droga, los asesinos y los extorsionadores" (El Faro, 2010). En esta labor, la Inspectoría de la PNC jugó un papel decisivo. Fue tan incisivo su trabajo que se aliaron los partidos de derecha en la Asamblea para pedir su revocación por parte del Presidente (El Mundo, 2011). Incluso intervinieron congresistas estadounidenses apoyando el trabajo de depuración que estaba llevando a cabo la inspectora Zaira Navas (WOLA, 2010).

Sin embargo, dos años después, ante la realidad del aumento de la violencia, el Presidente decidió deshacerse de estas personas, y volver a los fundamentales de combate a la violencia desde las estrategias que usó la derecha durante sus años de gobierno. Volvió a entronizar a los militares en el combate de la delincuencia, pero ahora con mayores responsabilidades que antes. Lo que la derecha no se atrevió a hacer por miedo a las críticas por parte de la izquierda y de las organizaciones sociales, no tuvo problema el presidente Mauricio Funes para llevarlo a cabo (UCA, 2012; Cañas, 2012).

Lo reseñado hasta ahora muestra la dificultad por llegar a un consenso sobre la mejor estrategia de enfrentamiento de la violencia en El Salvador. Los políticos siguen privilegiando la estrategia de la mano dura, la criminalización de la juventud y el uso de las maras como chivo expiatorio. ${ }^{9}$ Para los organismos de defensa de los derechos humanos, el combate de la delincuencia pasa por la lucha en contra de la marginación, la pobreza y la desigualdad (UCA, 2012). Otros han sostenido que el problema de los altos niveles de homicidios en El Salvador, en comparación con Nicaragua por ejemplo, se explica por el tipo de reformas de los aparatos estatales que se llevaron a cabo durante la transición a la democracia en la década de los 90 (Cruz, 2011a). En todo caso, "El origen fundamental de la violencia se halla en las instituciones del Estado. Para decirlo de manera un poco más complicada, se encuentra en la manera como el

9 A este respecto, el actual ministro de Defensa, cuyas ambiciones presidenciales son conocidas, ha sostenido que el $90 \%$ de los asesinatos son responsabilidad de las maras. Mientras que según datos oficiales manejados por la Policía Nacional Civil, sólo cerca del 30\% de los asesinatos son cometidos por los pandilleros (LPG, 2011). 
Estado centroamericano, sobre todo en los casos de El Salvador y Guatemala, creó sus instituciones para controlar a la población" (Cruz 2011b).

Todas estas consideraciones explican parte del origen de la violencia en El Salvador. Sin duda que hace falta mayor esfuerzo estatal para reducir las desigualdades en la distribución de la riqueza. Qué duda cabe que las decenas de miles de padres y madres de familias que abandonan su familia para buscar su vida en los Estados Unidos contribuye a una desestructuración de la vida familiar y hace más proclive a que niños sin orientadores terminen engrosando las filas de las maras. También se puede suponer que la incapacidad de la Policía Nacional Civil para combatir la corrupción dentro de sus filas o las debilidades de la fiscalía para llevar a cabo investigaciones de calidad que aporten pruebas contundentes en contra de los delincuentes tienen su cuota de responsabilidad en la ola delincuencial. Sin embargo, lo que no explican todos estos argumentos es por qué varía la violencia de un territorio a otro o de un año a otro en El Salvador.

Como puede observarse en el Cuadro 2, a lo largo de los años la violencia ha subido o bajado, sin que se sepa a ciencia cierta a qué se deben estas fluctuaciones. De igual modo, las tasas de homicidios tienen comportamientos distintos dentro del país, según el departamento en que uno se encuentra. El Cuadro 3 hace más visible este hecho. Invita a una comparación entre la tasa de homicidios y algunas variables que la literatura ha indicado como importantes para el control del nivel de violencia, como son el nivel de desarrollo humano, la densidad judicial (su capacidad burocrática), medida en término de número de oficinas por mil kilómetros cuadrados y densidad de la Fiscalía. Como puede observarse, los departamentos más violentos no necesariamente coinciden con los que tienen índice de desarrollo humano más bajo, ni con los que tienen menor capacidad fiscal o judicial. Es más, por muy extraño que pueda parecerse da la impresión que los departamentos con mayor nivel de desarrollo humano, en general, presentan mayores niveles de violencia. De igual modo, el problema no parece estar relacionado de un modo sencillo con la capacidad burocrática del sistema judicial. Si exceptuamos el caso de San Salvador, que representa un número claramente extremo de número de agencias del sistema judicial, el promedio de agencias es de 32,9 con una desviación estándar de 2,7. El Cuadro 3 muestra claramente que sería una equivocación sostener que la falta de capacidad burocrática judicial explica la variación en la tasa de homicidios en los departamentos. En todo caso, si efecto hubiera sería en el sentido contrario esperado por la teoría. Es decir, sería más factible afirmar que al aumentarse la capacidad operativa burocrática del sistema judicial en un departamento se dispara la tasa de homicidios. En este sentido, un problema evidente de la teoría es que no toma en cuenta que el aumento de la capacidad burocrática puede ser precisamente una respuesta al número de homicidios. En este sentido, la causalidad sería reversa. El aumento del número de agencias judiciales sería una mera respuesta a la necesidad de procesar un mayor número de problemas legales, especialmente los homicidios en dichos departamentos.

En el caso de la densidad de la Fiscalía, número de fiscales por habitantes, tampoco parece emerger un patrón coherente a partir de los datos presentados en el Cuadro 3. 
Cuadro 3. Comparación entre tasas de homicidios, capacidad burocrática judicial, capacidad de la fiscalía e índice de desarrollo humano por departamentos

\begin{tabular}{lcccc}
\hline Departamento & $\begin{array}{c}\text { Homicidios/ cien } \\
\text { mil habitantes }\end{array}$ & $\begin{array}{c}\text { Oficinas judiciales/mil } \\
\text { kilómetros cuadrados }\end{array}$ & $\begin{array}{c}\text { Fiscales/ } \\
\text { habitantes }\end{array}$ & IDH \\
\hline Ahuachapán & 46,2 & 22 & 2,5 &, 723 \\
Cabañas & 44,8 & 12 & 7,4 &, 704 \\
Chalatenango & 45,1 & 43 & 27,2 &, 737 \\
Cuscatlán & 50,2 & 27 & 3,7 &, 749 \\
La Libertad & 79,9 & 40 & 19,9 &, 788 \\
La Paz & 58,8 & 31 & - &, 757 \\
La Unión & 47,1 & 28 & 6,6 &, 698 \\
Morazán & 18,9 & 33 & 11,7 &, 695 \\
San Miguel & 61,7 & 49 & 5,3 &, 744 \\
San Salvador & 78 & 122 & 7,2 &, 81 \\
San Vicente & 38,8 & 26 & 8,8 &, 744 \\
Santa Ana & 70 & 44 & 5,4 &, 754 \\
Sonsonate & 87,9 & 28 & 3,9 &, 745 \\
Usulután & 38,9 & 41 & 3,9 &, 723 \\
\hline
\end{tabular}

Fuente: elaboración propia a partir de datos de Estado de la Nación (2011).

En efecto, observamos casos con bajas tasas de homicidios respecto del promedio (54,7), como Chalatenango y Cabañas, San Vicente y Morazán, con 45,1, 44,8, 38,8 y 18,9 respectivamente, pero sin patrón claro en el número de fiscales, que es de 27,2, 7,4, 8,8 y 11,7, respectivamente. Algo similar pasa con los casos de altos niveles de homicidios. No hay ningún patrón, comparando las tasas de homicidios de Sonsonate, La Libertad, San Salvador y San Miguel, que hace pensar que la cantidad de fiscales con que cuentan sería una causa de tal situación.

La consideración de los índices de desarrollo humano revela una imagen todavía más sorprendente. Una comparación somera entre las tasas de homicidios de los diferentes departamentos y el nivel de desarrollo humano revela que habría mayor nivel de homicidios en los departamentos con mayores niveles de desarrollo humano, como lo evidencian clamorosamente los casos de Morazán, La Unión y Cabañas con excepcionalmente bajos niveles de desarrollo humano (están a más de dos desviaciones estándares del promedio nacional que es de ,74 y desviación estándar de ,03), y bajos niveles de homicidios. Al 
contrario, Sonsonate, La Libertad y San Salvador representan los casos nacionales de mayores niveles de desarrollo humano, pero con tasas mucho más altas de homicidios.

Este análisis preliminar y somero de las principales variables asociadas al tema de la violencia muestra la dificultad de obtener una explicación fácil de por qué tantas personas son asesinadas en El Salvador. ${ }^{10}$ Quizá precisamente por esta razón los políticos han tendido a la respuesta más fácil y más visible, aunque no más eficaz. Poner a los militares en la calle, aumentar el carácter represivo del Estado, intimidando a los ciudadanos hasta ahora ha sido el camino privilegiado por izquierda y derecha. Porque no sólo nadie se ha dedicado a colectar y estudiar con rigurosidad los datos de la violencia, sino también porque las explicaciones basadas en el nivel de pobreza, desigualdad o disfuncionalidades del Estado hacen pensar en soluciones de largo plazo que no resuelven el dilema de baja aprobación en las encuestas de opinión pública a las que tienen miedo los políticos.

\section{2011 COMO AÑO PREELECTORAL}

A pesar de la preeminencia que adquirieron las desavenencias entre órganos legislativo y judicial y la violencia delincuencial durante el análisis anterior, cabe recordar que 2011 también fue un año preelectoral. Una vez que los diputados aparcaron las discusiones con la Corte y que resolvieron, a la satisfacción de ésta, el asunto de los candidatos independientes y el control de las cúpulas de los partidos sobre las listas, la preparación de la elección empezó a acaparar la atención.

Para quien observaba el proceso electoral, tres grandes preguntas marcaban la pauta. Por un lado, había incertidumbre respecto de cómo iban a reaccionar los electores frente al desempeño del FMLN como partido de gobierno. Desencuentros casi cotidianos entre el FMLN y Mauricio Funes hacían presagiar un castigo de los electores por tanta descoordinación. ${ }^{11}$ Se podía presumir, por otro lado, que un fuerte castigo a la izquierda en

10 Un análisis más fino de la interacción entre las variables mencionadas en el Cuadro 2 consistiría en tomar la vía de una regresión, con controles de contagio espacial para medir el impacto de cada variable. Pero debido a limitaciones de datos no se ha podido emprender este camino. En efecto, al hacer una regresión las variables capacidad burocrática del órgano judicial, número de fiscales e índice de desarrollo humano departamental sobre la variable dependiente tasa de homicidios, sólo el índice de desarrollo humano es significativo. Pero los resultados son presos del problema de multi colinearidad. Un test de Variance Inflation Factor en stata revela un vif cercano a 2. Puesto que multicolinearidad, antes que un problema estadístico consiste en un problema de datos (por eso Chris Achen (2000) lo llama un problema de micronumerosity), el próximo paso, más interesante, consistirá en analizar esta variable con datos de los 262 municipios con que cuenta El Salvador. Lastimosamente, por el momento no cuento con datos a este nivel.

11 Muchos analistas incluso suelen preguntarse si el FMLN puede aún considerarse como partido de gobierno. Los desencuentros entre Mauricio Funes y el FMLN empezaron incluso mucho antes de que éste accediera el poder. Siendo solamente un presidente electo, Funes desautorizaba públicamente a los miembros de su partido por cualquier declaración o iniciativa que estos tomaran sin consultarle. Desde que ocupa la presidencia de El Salvador, el partido FMLN ha ido perdiendo terreno en el gabinete de gobierno. Entre 2010 y 2011, el mandatario ha despedido a buena parte de los miembros del gobierno que provenían de las filas de este partido. (El Faro, 2011. "Los nuevos amigos del Presidente". http://elfaro.net/es/201109/noticias/5674/). En este período, por citar los casos más emblemáticos, el ministro de Seguridad Pública, el director del Organismo de Inteligencia del Estado, la ministra del Trabajo, todos fueron removidos por el gobernante para reemplazarlos con funcionarios de su confianza, desligados del FMLN. 
estos comicios estaría anunciando el final del paréntesis de la izquierda en la presidencia de El Salvador. En segundo lugar, por primera vez iba a competir en una elección el partido GANA, compuesto, según decíamos más arriba, de legisladores que se habían separado del partido ARENA. Desde 1994, los legisladores que se han desprendido de los partidos grandes, ARENA y FMLN, no han logrado su cometido. Estos partidos han terminado desaparecidos por no conseguir el 3\% de apoyo popular que requiere el código electoral. De modo que el desempeño electoral de GANA era una incógnita que se esperaba despejar. Finalmente, había mucha expectativa en torno a los posibles efectos de las nuevas disposiciones electorales, candidaturas independientes y listas desbloqueadas, forzadas por la Corte Suprema de Justicia. Había cierta expectativa, que finalmente no se verificó, que se pudiera generar un enfrentamiento entre candidatos de un mismo partido para, por medio de su reconocimiento por parte de los electores, cambiar su posición en la lista.

Luego de conocerse los resultados de las elecciones del 11 de marzo de 2012 se despejaron algunas dudas y, al mismo tiempo, se añadieron algunas complejidades para entender el proceso político salvadoreño. Desde el punto de vista de los resultados, el FMLN perdió las elecciones legislativas con una diferencia de 3\%. En cuanto a las elecciones municipales, no pudo retener muchas alcaldías emblemáticas que el partido había gobernado por más de 16 años, en ciertos casos. Estos resultados han envalentonado a ARENA que ganó las elecciones, obtuvo dos diputados más que el FMLN en la Asamblea Legislativa y retuvo el gobierno de la altamente simbólica Municipalidad de San Salvador. Por lo que muchos de sus líderes ya proyectan un probable triunfo para 2014, en la próxima elección presidencial. Aun así, sin embargo, no se despejó totalmente la duda acerca de la magnitud del descontento de la población con la labor del partido de izquierda. Cerca del $50 \%{ }^{12}$ de la población no acudió a las urnas y, según los reportes, al parecer la mayoría de quienes se ausentaron en las urnas son simpatizantes del partido de izquierda. En este sentido, se puede hablar de desilusión de muchos electores de la izquierda, pero no se puede hablar de un abandono masivo del partido de izquierda por parte de éstos.

Respecto del desempeño del nuevo partido Gran Alianza Nacional (GANA), éste creó la sorpresa. Es el único partido fundado en los últimos veinte años que ha tenido tal éxito electoral. Aun cuando no ha logrado reelegir a todos los diputados, 16 en total, con que cuenta con la legislatura que se termina, 2009-2012, se ha constituido en la tercera fuerza política nacional, con el 9,6\% de los votos y 11 diputados electos. De esta manera GANA ha desplazado al partido Conciliación Nacional, que dominó la legislatura como tercera fuerza política por más de 15 años. Lo interesante de la presencia de GANA en la legislatura es que, a primeras, parece desafiar la hegemonía de ARENA sobre la derecha en El Salvador. Desde 1994, con las primeras elecciones post Acuerdos de Paz

12 Históricamente la participación en elecciones municipales y legislativas en El Salvador son bajas y más bajas que las presidenciales. Pero, el nivel cercano al 50\% observado en estas elecciones rompe una tendencia de aumento observada en las elecciones de 2006 y 2009. Aun cuando, sin embargo, este nivel de participación estaría por encima del promedio del período 1994-2009, que es de 46,7\%. 
Alianza Republicana Nacionalista ha hegemonizado la derecha salvadoreña. Partidos como Conciliación Nacional (PCN) y los Demócrata-Cristianos (PDC) habían asumido su rol de partidos pequeños, especializados en nichos electorales, con una estrategia clientelar de movilización de sus electores, y como partidos que compiten por ponerse al servicio de ARENA. GANA, en cambio, ha intentado desafiar a ARENA. Además, su líder, el ex presidente Saca, no esconde sus pretensiones de volverse a postular a la presidencia de El Salvador. Por lo que los próximos años auguran una lucha fuerte dentro de la derecha salvadoreña.

En lo que concierne al comportamiento de los electores frente a la posibilidad histórica de contestar el poder de los dirigentes de los partidos, no hubo sorpresa alguna. Los electores respetaron escrupulosamente el orden establecido por los partidos. Respecto de los candidatos independientes tan sólo 19 personas se atrevieron a desafiar los obstáculos impuestos por los partidos. En todo caso, ya sea por las trabas, o por el poco tiempo con que contaban para prepararse para las elecciones, debido a la incertidumbre creada por las desavenencias entre la Corte Suprema y los diputados, ningún candidato independiente contó con apoyo social suficiente como para desafiar seriamente a los partidos. Así tanto el sistema de doble voto (por la bandera del partido o por algunas figuras de las listas), como los candidatos independientes no han tenido el impacto que la encarnizada lucha entre dirigentes partidarios, Corte Suprema de Justicia y organizaciones de la sociedad civil podían haber hecho suponer.

Por lo menos tres razones pueden explicar la aparente nula influencia de la nueva modalidad de competición electoral sobre los resultados y la distribución de curules en la Asamblea Legislativa. En primer lugar, puede que los actores independientes, dentro y fuera de los partidos, no hayan tenido tiempo para ajustar su estrategia a la nueva realidad electoral. En esto puede haber desempeñado un papel importante el estira y encoge entre el Legislativo y el Judicial, que hace que nadie podía anticipar cómo iba a terminar la batalla, por lo que no se pudieron preparar para lanzarse en la batalla electoral. Desde esta perspectiva, el factor tiempo pudo haber influido en este hecho.

Una segunda razón puede haberse debido al hecho de que, a diferencia de lo que ha ocurrido en otros períodos, no hay ningún movimiento de la sociedad civil con suficiente fuerza para generar una adhesión importante que concite el apoyo de los ciudadanos. Aun cuando la movilización de varias organizaciones hizo abortar el proyecto de sanción de los diputados a los magistrados de la Sala, ninguna organización descolló de manera especial y mostró interés en levantar un proyecto político propio vía algunas figuras independientes. Además, las organizaciones más vocales a favor de candidaturas independientes, que suelen ser en su mayoría de izquierda, no han manifestado últimamente mayor contradicción con el proyecto del FMLN.

Finalmente, tal vez la razón principal es que ya en cierta medida los partidos políticos salvadoreños tienen incorporada la estrategia de destacar algunas figuras "independientes" en su estrategia electoral legislativa y municipal. Puede argumentarse que hay dos tipos de estrategia electoral de los partidos. Los más pequeños, que suelen ganar sus curules en los distritos que eligen entre tres y cuatro diputados o como últimos por residuos en 
los distritos de mayor magnitud, privilegian una estrategia de segmentación dentro del distrito, combinado con populismo. Mientras que los partidos más grandes combinan una estrategia dual de competencia programática en los distritos grandes y una de patronage y clientelismo en los distritos más pequeños. Para ello los partidos pequeños tienen diputados bien anclados en sus distritos, muy conocidos y que construyen una estructura clientelar para mantenerse en el poder. Los partidos grandes, en cambio, suelen incorporar a algunas figuras populares a nivel local en su estrategia de campaña. Así estos partidos coordinan una estrategia general de movilización ideológica con otra de tipo clientelar. De este modo, pudieron haber neutralizado a cualquier competidor serio que intentara entrar en la competencia. Y este doble juego puede dificultar en el futuro la capacidad de los candidatos independientes para amenazar la hegemonía que los líderes partidarios tienen sobre la entrada a la Asamblea Legislativa. Ello, sin contar con la ventaja de las marcas de los partidos, los recursos económicos que ponen en desventaja a los independientes.

\section{CONCLUSIONES}

Del análisis de la coyuntura salvadoreña de 2011, se desprende que el país ha vivido momentos muy conflictivos. Las diferencias entre los poderes Legislativo y Judicial configuraron un escenario inédito en El Salvador desde el inicio de la democracia en 1994. Por primera vez algunos elementos del sistema judicial, concretamente cuatro magistrados de la Sala de lo Constitucional se pusieron en contra del statu quo ante, instaurado por los partidos políticos desde la firma de los Acuerdos de Paz. Las decisiones de los jueces dieron lugar a una alianza tácita entre organizaciones de la sociedad civil y los jueces. Analizado desde el punto de la gobernabilidad (Artiga, 2008), no cabe duda que fueron momentos muy convulsivos para el sistema político. Básicamente los principales poderes estatales estuvieron enfrentados por un espacio de tiempo en que cada uno cuestionaba la legitimidad del otro.

La legitimidad de las instituciones se vio cuestionada tanto desde dentro (por la pugna entre los órganos) como desde fuera por los resultados acumulados de inefectividad en el combate en contra de la violencia y el bajo crecimiento económico. La literatura politológica ha subrayado ampliamente la necesidad de evitar la deslegitimación de las instituciones (Diamond, 1999). Si bien la preocupación por una vuelta a las dictaduras de antaño que motivó la discusión en torno a los impactos de la falta de resultados de las democracias latinoamericanas no parece de actualidad, pero es indudable que ello afecta la calidad de la democracia. Siguiendo a Malone (2010), puede plantearse que el respeto por los procedimientos legales puede verse seriamente afectado por estos problemas de efectividad y legitimidad de las instituciones estatales.

En este sentido, el fracaso del gobierno de la izquierda en el combate de la violencia puede llevar a un mayor alejamiento y descreimiento de los ciudadanos en el sistema político. $\mathrm{Si}$ al final se prueba que la alternancia política no ha servido para resolver los problemas puede que los ciudadanos terminen abrazando opciones extrasistémicas peligrosas. En este sentido quizás pueda ser aleccionador reflexionar por qué los guatemaltecos 
escogieron en las urnas la opción del ex general Otto Pérez Molina, luego del estrepitoso fracaso, especialmente en materia de combate del crimen, un gobierno de tendencia izquierdista. Ello, no equivale a afirmar que vaya a suceder en breve lo mismo en el caso salvadoreño. El sistema de partidos salvadoreño sin duda tiene resortes institucionales mucho más engrasados que el guatemalteco. Algunos incluso han sostenido que en este último caso hay que hablar de "partidos sin sistemas" (Sánchez, 2009). Sin embargo, no está de más preguntarse si los episodios de 2011 pueden suponer el inicio de un proceso de desestructuración del sistema de partidos salvadoreño. El tiempo que pueda durar este proceso y la reversibilidad o no de sus consecuencias es una pregunta empírica que sólo se podrá medir en el tiempo. De todas maneras, es llamativo el proceso de fragmentación de la derecha iniciado a raíz de los resultados electorales de 2009. Este contexto es interesante porque por primera vez desde los Acuerdos de Paz parece que con GANA puede que haya nacido un competidor para ARENA, que lucha por ocupar su mismo espacio ideológico. La eventual candidatura de Saca a las presidenciales de 2014 y sus resultados determinarán si GANA se convierte en una alternativa política viable a la derecha de ARENA. Todo ello combinado además con el hasta ahora fracaso gubernamental de la izquierda y el protagonismo que han empezado a tener los jueces, aliados con actores de la sociedad civil. Ello significa que habrá que prestar atención a la evolución de las relaciones entre actores sociales, políticos e institucionales en los próximos meses. De esta interacción dependerá saber si los acontecimientos reseñados en este trabajo tan solo han tenido efectos coyunturales pasajeros o si han calado hondo en la vida política salvadoreña.

\section{REFERENCIAS}

Achen, Christopher H. 2000. "Why Lagged Dependent Variables Can Suppress the Explanatory Power of Other Independent Variables". Paper presented at Annual Meeting of the Political Methodology Section of the American Political Science Association, UCLA.

Aguilar, Jimena. 2010. "Ex presidente Corte Suprema pide a Asamblea desobedecer fallo de Sala de lo Constitucional". http://www.elfaro.net/es/201008/noticias/2375/.

Aguilar, Jimena. 2011. Gana dijo a embajada EUA que Funes prácticamente los adoptó. http:/ / www.wikileaks.elfaro.net/es/201110/notas/6133/.

Artiga-González, Álvaro. 2008. Gobernabilidad y democracia en El Salvador: bases teóricas y metodológicas para su medición. UCA Editores, San Salvador El Salvador.

Artiga-González, Álvaro. 2004. Elitismo competitivo: dos décadas de elecciones en El Salvador (19822003), UCA Editores, San Salvador.

Arauz, Sergio. 2011. "Sala de lo Constitucional quita a partidos monopolio del derecho a impugnar elecciones". http://www.elfaro.net/es/201106/noticias/4530/).

Cañas, Roberto. 2012. "Seguridad pública en manos de militares". http://www.elfaro.net/es/201201/ opinion/7423/.

Co-Latino. 2011. "ANEP pide a diputados frenar ataques a la democracia". http://www.diariocolatino. com/es/20110621/nacionales/93720/ANEP-pide-a-diputados-frenar-ataques-a-la-democracia.htm.

Cruz, José Miguel. 1997. "Los factores posibilitadores y las expresiones de la violencia en los noventa". ECA. 558.

Cruz, José Miguel. 2011a. "Criminal Violence and Democratization in Central America: The Survival of the Violent State". LAPS. Winter Issue. 
Cruz, José Miguel. 2011b. "El origen de la violencia". El Faro. http://www.elfaro.net/es/201101/ opinion/3439/.

Diamond, Larry. Developing Democracy Toward Consolidation. Johns Hopkins University Press, Baltimore and London.

Equipo Regional de Monitoreo y Análisis de Derechos Humanos en Centroamérica. 2011. "Informe sobre Derechos Humanos y Conflictividad en Centroamérica 2010-2011". http://www.fespad.org.sv/ documentos/informe-ddhh-2010-2011.pdf

El Mundo. 2011. CSJ frena investigación de Inspectora Navas". http://elmundo.com.sv/ csj-frena-investigacion-de-inspectora-navas.

Freedman, Elaine. 2011. Decreto 743: ¿Qué hay tras todo esto? Revista Envío. http://www.envio.org. $\mathrm{ni} /$ articulo/4360.

FESPAD. 2005. “La Crisis en la construcción del Estado de Derecho. El Sistema Político Electoral en El Salvador". Citado en FESPAD INFO. Año 3. No. 9.

FESPAD. "Ante la crisis social que vive El Salvador". FESPAD INFO. Año 3. No. 9.

FUSADES. 2010. "Perfil y comportamiento político de los diputados que abandonaron a sus partidos". Boletín de Estudios Políticos. Boletín No. 2 Oct/Nov 2010.

IUDOP. 2011. “Los salvadoreños y salvadoreñas evalúan la situación del país a finales de 2011 y opinan sobre las elecciones de 2012. Boletín de prensa Año XXVI, No. 2.

La Prensa Gráfica:jueves 22 /12/2011. http:/ /www.laprensagrafica.com/el-salvador/judicial/238781pandilleros-cometen-el-2985-de-homicidios-pnc.html "Pandilleros comenten cerca del 29,85\% de homicidios: PNC. En cambio para el militar director de la policía el $90 \%$ de los homicidios son responsabilidad de los pandilleros.

La Prensa Gráfica: 19/12/2011: http:/ /www.laprensagrafica.com/el-salvador/judicial/238230-pnc-esla-institucion-mas-denunciada-por-violacion-a-los-ddhh.html).

López Bernal, Carlos Gregorio. 2011. Seguridad: Reviviendo los fantasmas del pasado. http:/ /www. elfaro.net/es/201111/opinion/6650/.

Malone, Mary Fran. 2010. “The Verdict is In: The Impact of Crime on Public Trust in Central American Justice Systems. Journal of Politics in Latin America, 2, 3, 99-128.

Martínez, Carlos. 2010. Corte Suprema habilita candidaturas independientes para 2012. http://www. elfaro.net/es/201007/noticias/2201/.

PNUD (2004). "La democracia en América Latina. Hacia una democracia de ciudadanos y ciudadanas". Guatemala: Programa de Naciones Unidas para el Desarrollo.

Ribera, Ricardo. 2012. "Gramática Presidencial”. Publicado el 31 de enero de 2012. http:// elfaro.net/ es/201201/opinion/7424/.

Ribera, Ricardo, 2012. "Más fuerza al recambio". http:/ /www.elfaro.net/es/201203/opinion/7983/.

Sánchez, Omar (2009). "Party Non-Systems a Conceptual Innovation". Party Politics. 15(4) pp. 487-520.

UCA. Enero de 2012. Pronunciamiento "Ante los nombramientos de dos generales al frente del Ministerio de Justicia y Seguridad Pública, y la Policía Nacional Civil". http:/ / www.uca.edu.sv/noticias/nota. php?texto $=586566045$.

WOLA. 2010. "Congresista estadounidense insta apoyo hacia la Inspectora General Navas y el presidente Funes". http://www.wola.org/es/noticias/congregista_estadounidense_insta_ apoyo_hacia_la_inspectora_general_navas_y_el_presidente_fu.

Roody Réserve. Candidato a doctor en Ciencia Política por la Pontificia Universidad Católica de Chile. Email: reserve@uc.cl 
